\section{LAS LEGUMINOSAS GRANO EN LA AGRICULTURA ESPAÑOLA Y EUROPEA}

\author{
María José González-Bernal \\ Consejo Superior de Investigaciones Científicas \\ mjgonzalez@ias.csic.es \\ Diego Rubiales \\ Consejo Superior de Investigaciones Científicas \\ diego.rubiales@ias.csic.es
}

Cómo citar este artículo/Citation: González-Bernal, M. J. y Rubiales, D. (2016). Las leguminosas grano en la agricultura española y europea. Arbor, 192 (779): a311. doi: http://dx.doi. org/10.3989/arbor.2016.779n3001

Recibido: 08 marzo 2016. Aceptado: 06 mayo 2016.

RESUMEN: A pesar de la larga tradición de cultivo y consumo de leguminosas en España y de sus conocidos beneficios medioambientales mejorando la fertilidad de los suelos, su cultivo ha disminuido constantemente en los últimos 50 años siendo reemplazadas por otros cultivos que se han adaptado mejor a los avances tecnológicos y resultan más rentables al agricultor. El consumo de legumbres ha descendido en España notablemente desde los $13 \mathrm{~kg} /$ persona/año en la década de los 60, hasta los poco más de 3 en la actualidad, pero aun así, importamos hoy alrededor del $85 \%$ de las judías, el $75 \%$ de los garbanzos y el $60 \%$ de las lentejas que consumimos. Asimismo, el descenso del consumo de legumbres ha ido asociado a un incremento del consumo de carne, lo que ha aumentado el consumo de leguminosas para pienso, sobre todo soja, pero no así su cultivo por lo que importamos casi 5 millones de toneladas de soja al año, lo que supone el $95 \%$ de las importaciones de leguminosas. Esta tendencia es similar a la encontrada en el resto de Europa lo que genera dos dependencias preocupantes que solo pueden aliviarse aumentando el cultivo de leguminosas. Por un lado está la dependencia de las importaciones de proteína vegetal (70\%), a lo que se une la de fertilizantes nitrogenados (80\%). Además, la producción de estos fertilizantes requiere gran energía, básicamente gas natural, del cual la UE importa del orden del $60 \%$ de sus necesidades. Esta dependencia de las importaciones de proteína, sobre todo soja, no solo supone un riesgo galopante para la balanza de pagos, sino también de seguridad alimentaria, poniendo a nuestra industria cárnica en manos de las oscilaciones del precio de la soja.

PALABRAS CLAVE: legumbres; garbanzos; habas; lentejas; guisantes; judías; soja.

\section{GRAIN LEGUMES IN SPANISH AND EUROPEAN AGRICULTURE}

Copyright: (C) 2016 CSIC. Este es un artículo de acceso abierto distribuido bajo los términos de la licencia Creative Commons Attribution (CC BY) España 3.0.

ABSTRACT: Grain legume cultivation is continuously decreasing in Spain in spite of the long tradition of their cultivation and consumption and their well-known environmental benefits by improving soil fertility. Grain legumes have been replaced in rotations by other crops that have adapted more quickly to technological progress and are more profitable for farmers in the short term. A similar change is taking place in Europe. This generates two major dependencies that can only be alleviated by increasing legume cultivation. On the one hand, Europe faces an increasing dependency on nitrogen fertilizers, using up to 10 million tons yearly, of which about $80 \%$ are imported. In addition to this, fertilizer production uses large amounts of energy, being highly dependent on natural gas, of which the EU imports $60 \%$ of its requirements. On the other hand, EU countries import $70 \%$ of their requirements as vegetable protein. In Spain, we import 4.7 million tons of grain legumes yearly, most of which is soybean ( $95 \%$ of the total). The decline in human consumption does not justify the reduction in cultivation, as we import $85 \%$ of the dried beans, $60 \%$ of the lentils and $75 \%$ of the chickpeas consumed in Spain. This dependency on imports, particularly on soybean, poses a serious threat to the economy as it makes the raw feed industry, and therefore most of the meat industry, vulnerable to fluctuations in the world soybean price.

KEYWORDS: grain legumes; pulses; chickpea; faba bean; lentil; pea; bean; soya. 


\section{INTRODUCCIÓN}

Gracias a su papel mejorante de la fertilidad de los suelos por la asociación simbiótica con bacterias fijadoras de nitrógeno atmosférico (Ramírez-Bahena y col., 2016), las leguminosas son un componente imprescindible en las rotaciones de cultivo dentro de una agricultura sostenible. Además son una valiosa fuente de proteína tanto para alimentación animal (Rubio y Molina, 2016) como humana, con conocidos beneficios para la salud (Arnoldi y col., 2015; DelgadoAndrade y col., 2016) siendo uno de los pilares de la dieta mediterránea.

Las leguminosas están entre las primeras plantas cultivadas por el hombre junto a los cereales de modo que las grandes civilizaciones las incluyeron pronto en su dieta. Así, habas (Vicia faba), garbanzos (Cicer arietinum) y lentejas (Lens culinaris) están muy arraigadas a la cultura agronómica y culinaria de Asia y Europa. Otros cultivos como la judía (Phaseolus vulgaris) se introdujeron en Europa tras la conquista de América. No obstante, y a pesar la larga tradición de cultivo y consumo en España, de todos estos bien conocidos beneficios, y de las distintas ayudas al sector, su cultivo ha disminuido constantemente en los últimos 50 años, siendo reemplazadas por otros cultivos que se han adaptado mejor a los avances tecnológicos y resultan más rentables al agricultor. Como ejemplo, la superficie cultivada de leguminosas, a nivel mundial es actualmente 3,5 veces menor que la de cereales (FAOSTAT, 2013), alcanzando rendimientos medios más bajos $(1.500 \mathrm{~kg} / \mathrm{ha}$ leguminosas vs $3.500 \mathrm{~kg} /$ ha cereales) y lo que es más preocupante, esta diferencia de rendimientos como resultado de la mejora de las técnicas de producción y de las variedades es cada vez mayor, aumentando en España cada año una media de $52 \mathrm{~kg} / \mathrm{ha}$ para el trigo (Triticum aestivum), y menos de $10 \mathrm{~kg} / \mathrm{ha}$ en el caso de garbanzo, lenteja, altramuz (Lupinus spp.), haba o guisante (Pisum sativum).

A esto se unen los hábitos modernos de consumo que han hecho que el consumo de legumbres en España haya disminuido constantemente desde los 13 $\mathrm{kg} /$ persona/año en la década de los 60 , hasta los poco más de 3 de la actualidad. Este es ligeramente superior a la media europea $(2,7 \mathrm{~kg} /$ persona/año), pero muy inferior a la media mundial ( $7 \mathrm{~kg} /$ persona/año). Los garbanzos son la legumbre más consumida en España $(1,25 \mathrm{~kg} /$ persona/año) seguidos de judías y lentejas (0,93 kg/persona/año cada una). Esta disminución del consumo no justifica de por sí la disminución del cultivo, puesto que la producción nacional está muy por debajo del consumo, importándose en España hoy alrededor del $85 \%$ de las judías, el 75\% de los garbanzos y el $60 \%$ de las lentejas que consumimos.

El descenso del consumo humano de legumbres en España y Europa ha ido asociado a un incremento del consumo de carne desde los $20 \mathrm{~kg} /$ persona/año en la década de los 60, hasta los 50 en la de los 80 a partir de la cual hubo una tendencia a la estabilización, siendo de $51 \mathrm{~kg} /$ persona/año en la actualidad. Este mayor consumo de carne supuso un aumento del consumo de leguminosas para pienso, pero no así en su cultivo. Esto lo resolvió la industria de piensos con la importación de soja (Glycine max), que no ha dejado de aumentar desde los años 70, lo que a su vez, no ha ayudado mucho al desarrollo del cultivo de otras leguminosas para pienso que cada vez han ido quedándose más descolgadas a pesar de su potencial. Y es que como en todo, no hay desarrollo sin inversión en innovación.

Esta tendencia a la baja del cultivo de leguminosas en España (Figura 1) es similar a la encontrada en el resto de Europa (Figura 2), aunque contrasta con la situación mundial (Figura 3) donde, aunque baja el cultivo de habas y guisante, aumenta espectacularmente el cultivo de la soja, y en general de todas las leguminosas tropicales, pero también el de otras de clima frío como lentejas y garbanzos (Rubiales y Mikic, 2015). El descenso del cultivo de leguminosas en Europa genera dos dependencias preocupantes. Por un lado, el consumo de fertilizantes nitrogenados en España fue superior a 800.000 toneladas en 2012 , de las cuales importamos el 65\%. En la UE el consumo superó los 10 millones de toneladas anuales de las cuales el $81 \%$ fue importado. Además, la producción de estos fertilizantes requiere gran energía, básicamente gas natural del cual también somos dependientes del exterior, importándose tanto en España como en la UE del orden del $60 \%$ de sus necesidades. Por otra parte, la UE importa el $70 \%$ de la proteína vegetal que consume, de la cual no todo son leguminosas. España consume más de 4,8 millones de toneladas de leguminosas grano al año, mientras que no llega a producir ni 0,3. La gran mayoría del consumo de leguminosas en España corresponde a la soja (4,3 millones de toneladas), seguido a mucha distancia por guisante seco $(0,2)$, garbanzo y lenteja $(0,1)$, judía $(0,05)$ y haba $(0,03)$.

En un intento de corregir esta disminución del cultivo de leguminosas, la UE ha ido creando una serie de ayudas con distintos formatos, unas veces basadas en subvenciones a la superficie, otras a la producción, que han tenido un efecto persuasorio mientras han 
durado las ayudas, pero que no han servido para consolidar al sector. Actualmente existe la posibilidad de una ayuda de unos $100 €$ /ha para las legumbres de calidad (judías, lentejas y garbanzos) acogidas a una denominación protegida o en agricultura ecológica, lo cual representa hoy sólo unas 5.000 has, quedando la mayoría (más del $80 \%$ del total) de la producción de legumbres de calidad con destino a la alimentación humana (lentejas, garbanzos y judías) fuera de estas áreas sujetas a protección que pueden recibir esa ayuda. Además la actual Política Agraria Común (PAC) ha beneficiado al cultivo de leguminosas con las ayudas asociadas al Pago Verde siempre que se respeten determinadas prácticas medioambientales, entre las que se incluye la diversificación de cultivos. Esto está despertando el interés en el sector y se nota un repunte en el cultivo de leguminosas. Esta inesperada demanda está mostrando la debilidad del sector al no disponerse de la suficiente cantidad de semilla certificada de calidad de variedades modernas suficientemente adaptadas a nuestras condiciones, lo que ha vuelto a poner de manifiesto la falta de planificación. Y es que, lo mismo que no podemos basar nuestra producción de piensos en la importación de soja, tampoco podemos basar nuestro cultivo de leguminosas en la importación de técnicas o de variedades desarrolladas en otras condiciones. Aunque en España existen meritorios programas de investigación y agronomía en leguminosas, se había entrado en un círculo vicioso en el que la reducción del cultivo había reducido la inversión en el desarrollo y registro de nuevas variedades, así como en la multiplicación de semilla certificada.
Considerando esto, a continuación se muestran los datos más relevantes de las leguminosas grano en España, Europa y el mundo utilizando como fuente la información de la FAO de los últimos 50 años disponibles (1963-2013). Aunque anteriormente nos hayamos referido a datos actuales de la Unión Europea, debido a que durante este periodo se han ido incorporando nuevos países a la UE, en el análisis de la serie histórica, haremos referencia a la totalidad de Europa para poder comparar un área geográfica constante. Nuestro estudio puede discrepar con otros en el sentido de que agrupamos especies que a veces vemos separadas en leguminosas grano (judías secas, lentejas y garbanzos), proteaginosas (guisante seco, altramuz dulce, habas) y oleaginosas (soja). Incluiremos en el estudio las leguminosas comercializadas en forma de grano, lo que incluye a la soja, puesto que es una leguminosa de la que se cosecha y comercializa el grano y que tiene alto contenido proteico. Cierto es que la soja tiene un doble uso dado su alto contenido en aceite, lo que suele llevar a catalogarla como cultivo oleaginoso en vez de proteaginoso, pero más cierto es que sigue siendo una leguminosa de cuyo grano obtenemos proteína que es lo que aquí nos ocupa.

\section{EVOLUCIÓN HISTÓRICA DE LAS LEGUMINOSAS GRANO}

La superficie cultivada total de leguminosas grano en España (Figura 1) ha disminuido preocupantemente en la serie de 50 años estudiada. En la actualidad se cultivan en torno a 200.000 hectáreas de leguminosas grano en España, 530.000 menos que en la década de los 60 .

Figura 1. Evolución de la superficie cultivada (millones de hectáreas), la producción e importación (millones de toneladas) de leguminosas grano en España en los últimos 50 años (FAOSTAT, 2013). Eje Y cortado en 1 millón por cambio de escala.

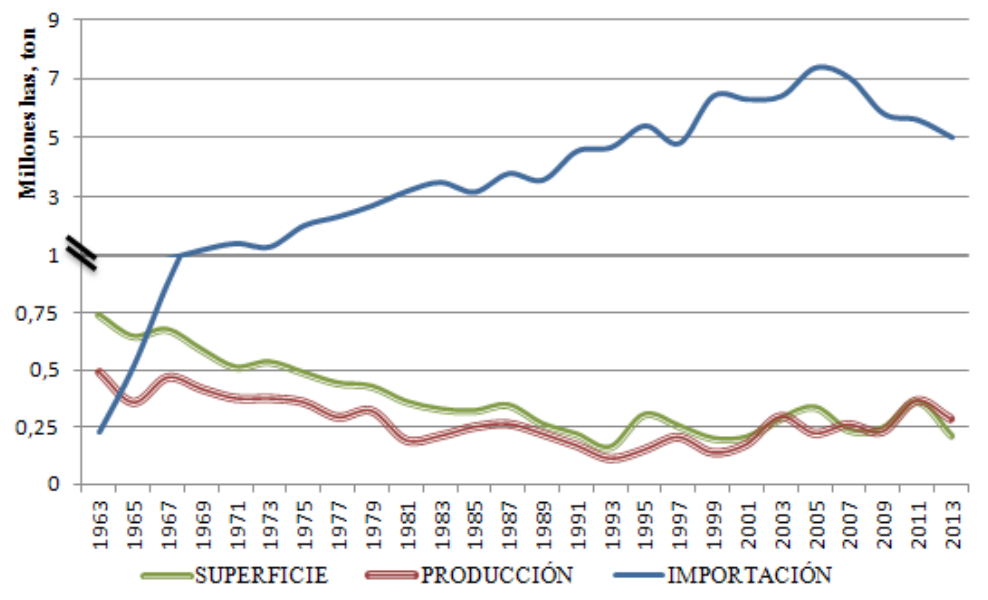


En Europa, la superficie cultivada de leguminosas grano también cae notoriamente $(10,4$ millones de hectáreas) en los 50 años estudiados, cultivándose en la actualidad 5,7 millones de hectáreas (Figura 2), en contraposición con lo que ocurre a nivel mundial (Figura 3), donde la superficie ha ido aumentando progresivamente con el paso de los años, cultivándose hoy en día en torno a 170 millones de hectáreas.

A pesar de la menor superficie dedicada al cultivo de leguminosas grano en España, la producción (Figura 1), aunque con fluctuaciones, podemos decir que ha disminuido a menor escala que la superficie, produciéndose en la actualidad más de 280.000 toneladas. A nivel europeo nos encontramos con que, aunque la superficie cultivada disminuye, la producción (Figura 2) se mantiene e incluso aumenta (siendo de 10,7 millones de toneladas en la actualidad), gracias a la mejora de los rendimientos, que es superior a la de España. En el mundo la producción aumenta a mayor escala que la superficie (Figura 3), produciéndose 336 millones de toneladas de leguminosas grano en la actualidad.

Tanto en España como Europa somos deficitarios con producciones que no satisfacen la demanda (Figuras 1 y 2) con importaciones que han aumentado de forma alarmante en los últimos 50 años y que oscilan durante los últimos 15 años en torno a los 5-7 millones de toneladas en España y en torno a los 40-50 millones de toneladas en Europa.

La soja es la leguminosa más consumida y a la vez menos cultivada y producida en España (solo 500 hectáreas y 1.400 toneladas en 2013, Figura 4), por lo que es la más importada (Figura 6). Importamos del orden de 4,7 millones de toneladas (semilla más torta de soja) anualmente (Figura 6), lo que supone un $96 \%$ del volumen total de importaciones de leguminosas grano. Las posibilidades de expansión del cultivo de soja en España son muy limitadas al ser un cultivo de verano con altas necesidades hídricas. Tiene un claro nicho en ciertas fincas de riego en segunda cosecha como sustituto del maíz, cuya expansión o no dependerá del precio de la soja. Aún así, las posibilidades de expansión de la soja a nivel nacional tienen un techo claro ya que nuestra mayor superficie de cultivo es de secano. La única alternativa a medio-largo plazo sería el desarrollo de variedades adaptadas a siembras más tempranas y con menos necesidades hídricas. En Europa el cultivo de la soja ha experimentado un incremento espectacular en la última década (Figura 7), siendo hoy la única leguminosa cuya superficie aumenta, desbancando incluso al guisante. Es la leguminosa más cultivada, con 3,2 millones de hectáreas, lo que supone más del $55 \%$ de las hectáreas totales cultivadas de leguminosas grano, y la más producida, con 6 millones de toneladas actualmente. Esto ha ido unido a los esfuerzos de los productores de los países de la cuenca del Danubio, donde la climatología permite el cultivo de soja en verano con pocos riegos. A nivel mundial (Figura 10) el aumento del cultivo de la soja empezó antes, representando en la actualidad el 65\% de la superficie cultivada total de leguminosas grano, superior a 111 millones de hectáreas. La producción mundial (Figura 11) es superior a los 278 millones de toneladas, concentrándose el $80 \%$ de la producción entre Estados Unidos (35\%), Brasil (28\%) y Argentina (17\%). El rendimiento actual a nivel mundial de la soja es de $2.500 \mathrm{~kg} / \mathrm{ha}$, con una ganancia anual de $25 \mathrm{~kg} /$

Figura 2. Evolución de la superficie cultivada (millones de hectáreas), producción e importación (millones de toneladas) de leguminosas grano en Europa en los últimos 50 años (FAOSTAT, 2013).

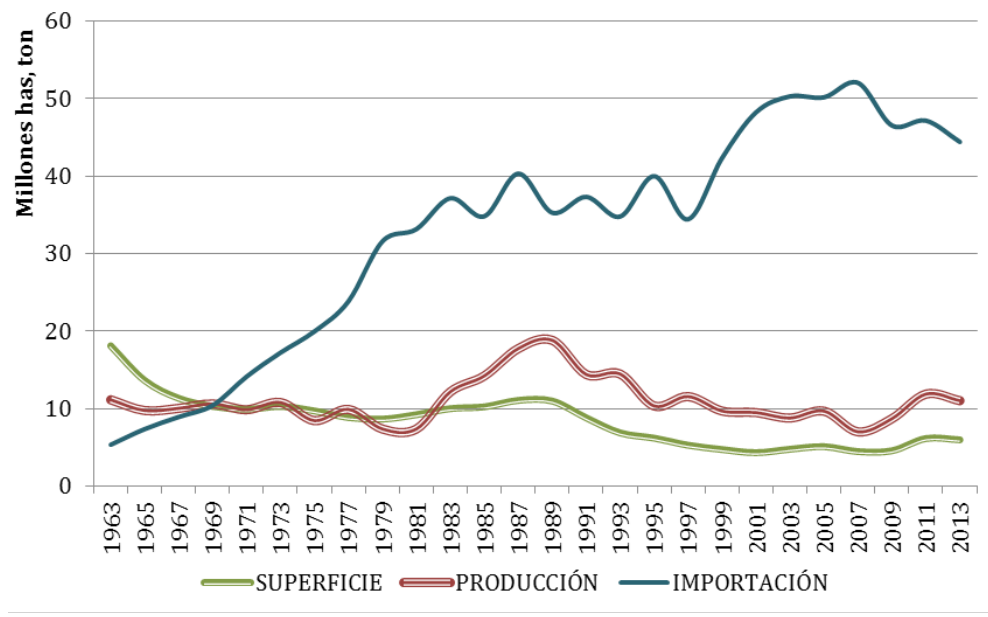


Figura 3. Evolución de la superficie cultivada (millones de hectáreas) y producción (millones de toneladas) de leguminosas grano en el mundo en los últimos 50 años (FAOSTAT, 2013).

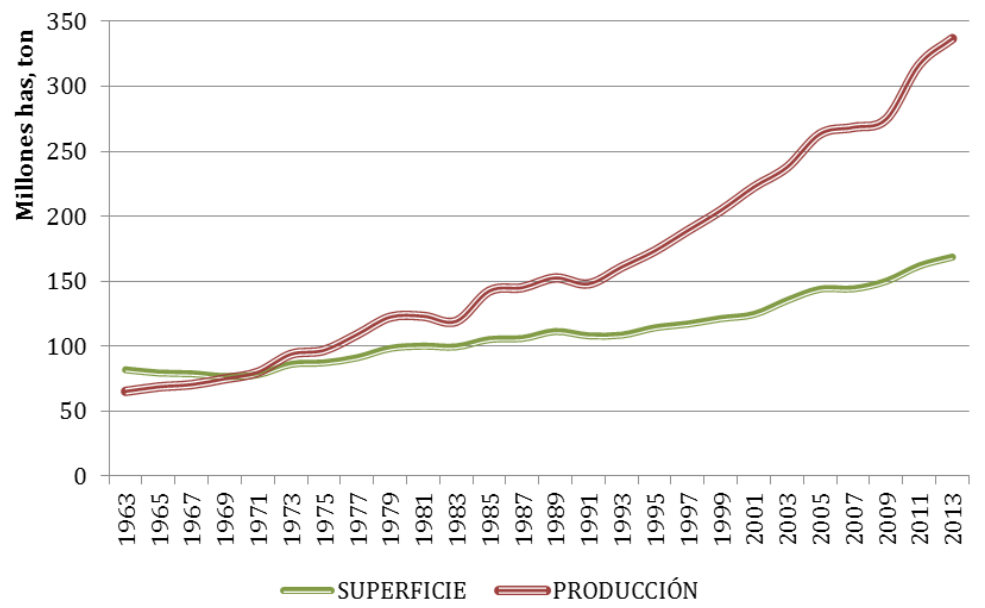

ha/año, siendo la leguminosa que ha experimentado un mayor incremento de rendimiento en los años estudiados. En España, el rendimiento es de $2.800 \mathrm{~kg} /$ ha con una ganancia anual de $25 \mathrm{~kg} / \mathrm{ha} / \mathrm{año}$, mientras que en Europa es de $1.900 \mathrm{~kg} / \mathrm{ha}$ con una ganancia de $32 \mathrm{~kg} / \mathrm{ha} /$ año.

La leguminosa más cultivada en España es el guisante seco, con una superficie de 122.000 hectáreas, lo que supone casi el $60 \%$ de la superficie cultivada de leguminosas grano en España. De hecho, el guisante es la única leguminosa grano cuyo cultivo ha aumentado en España en el periodo estudiado, particularmente desde 1993, habiendo llegado a superar las 240.000 hectáreas en el 2011 (Figura 4). La situación europea es completamente distinta ya que el guisante seco ha sido durante casi todo el periodo analizado la leguminosa grano más cultivada con entre 4 y 7 millones de hectáreas hasta 1993, cayendo desde entonces hasta los 1,7 millones actuales, siendo su cultivo superado por la soja en los últimos 10 años (Figura 7). A nivel mundial el guisante seco ocupa la cuarta posición, manteniéndose relativamente constante el cultivo a lo largo de los años, con 6,7 millones de hectáreas hoy en día. Analizando la producción, el guisante seco es también la leguminosa grano más producida en España (Figura 5), con casi 178.000 toneladas. Los principales productores de guisante en España son Castilla La Mancha y Castilla y León. La producción actual de guisante seco en Europa es de 3 millones de toneladas, destacando Rusia con el $53 \%$ del total, seguido de Francia (27\%) y Ucrania (10\%), mientras que en el mundo se producen 11,4 millones de toneladas y el

Figura 4. Evolución de la superficie (hectáreas) de leguminosas grano en España en los últimos 50 años (FAOSTAT, 2013).

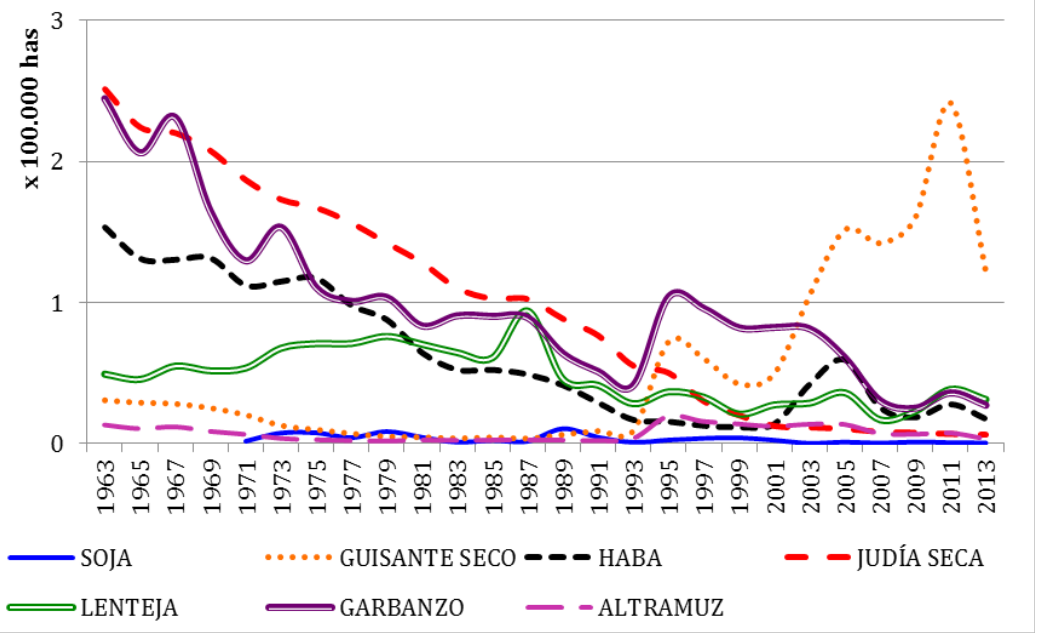


Figura 5. Evolución de la producción (toneladas) de leguminosas grano en España en los últimos 50 años (FAOSTAT, 2013).

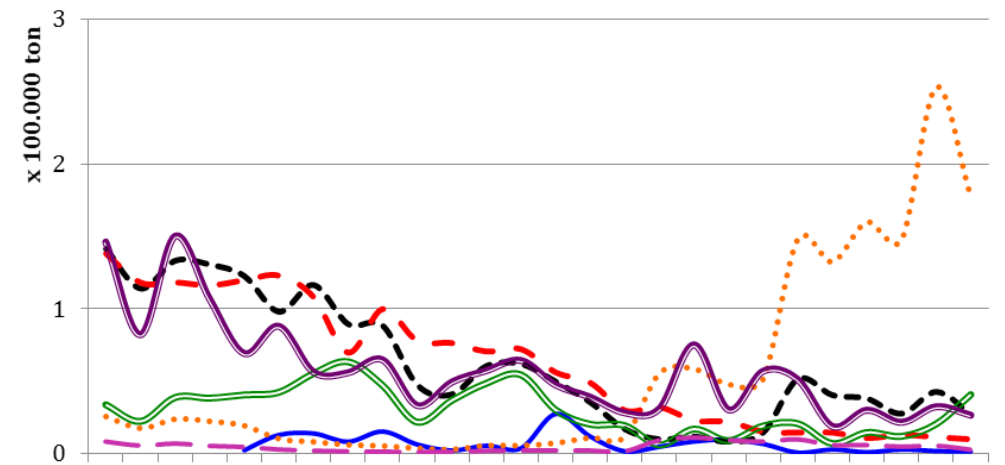

\%

$\begin{array}{ll}\text { SOJA } & \cdots . . \text { GUISANTE SECO } \\ \text { LENTEJA } & \text { - HABA GARBANZO - - ALTRAMUZ }\end{array}$

principal país productor es Canadá. El rendimiento actual de guisante seco en España es de $1.500 \mathrm{~kg} / \mathrm{ha}$, inferior al de Europa ( $1.800 \mathrm{~kg} / \mathrm{ha}$ ) y el Mundo ( 1.700 $\mathrm{kg} / \mathrm{ha}$ ), y el incremento anual de rendimiento también es el menor, $8 \mathrm{~kg} / \mathrm{ha} / \mathrm{año}$ en España frente a los $30 \mathrm{y}$ 17 de Europa y el mundo respectivamente.

Las importaciones de guisante en España (Figura 6) y Europa (Figura 9) han ido fluctuando en función al precio de la soja. En los años en los que la demanda de soja mundial aumenta, el precio también aumenta, y aumenta la importación de otras leguminosas, siendo el guisante la primera opción. La importación española ha ido oscilando alrededor del medio miIlón de toneladas en la década de los 90, habiendo superado el millón en 2005, para caer en la última década hasta las 32.000 toneladas (lo que supone el
$16 \%$ del consumo de guisante seco), gracias a, entre otras cosas, la mayor producción nacional anteriormente comentada. El guisante se presenta por tanto como la opción más viable para reducir las importaciones de soja, ya que es la única leguminosa grano cuyo cultivo aumenta en España demostrando su potencial y adaptación, y es a la vez la más aceptada por la industria de piensos. La importación en Europa es de 613.000 toneladas, lo que supone el $22 \%$ de la demanda total del continente.

En España, el cultivo de la judía seca ha sufrido un gran descenso en los últimos 50 años, siendo en la actualidad la superficie cultivada de 6.500 hectáreas, mientras que superaba las 200.000 en la década de los 60 (Figura 4). A pesar de ello, la producción no ha bajado proporcionalmente a la superficie, siendo hoy

Figura 6. Evolución de las importaciones (toneladas) de leguminosas grano en España en los últimos 50 años (FAOSTAT, 2013). Eje Y cortado en 1 millón por cambio de escala.

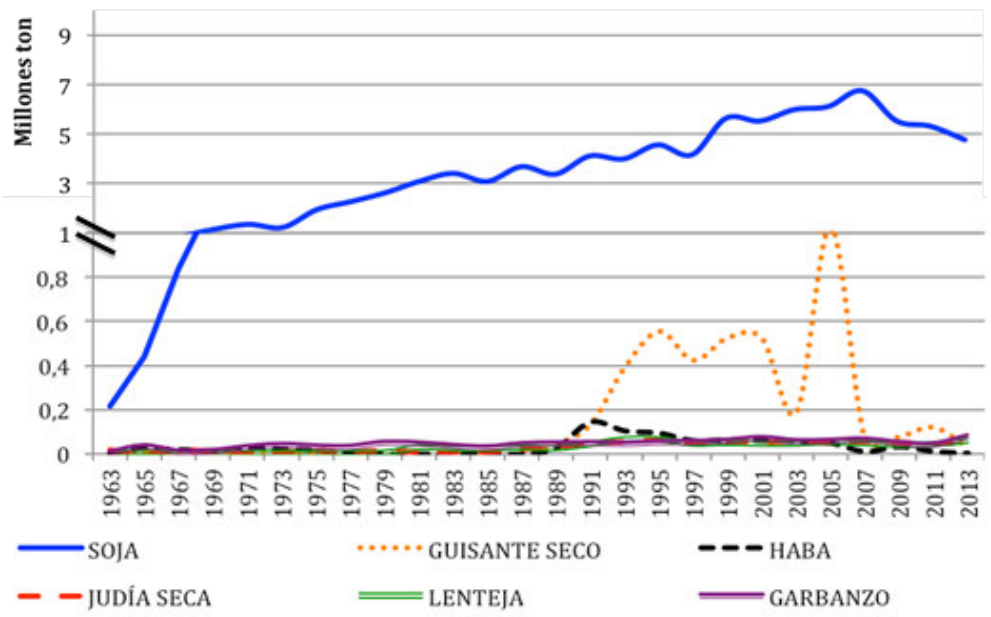


en día de 10.000 toneladas (Figura 5), gracias al mejor rendimiento obtenido ( $1.600 \mathrm{~kg} / \mathrm{ha}+22 \mathrm{~kg} / \mathrm{ha} / \mathrm{año})$. La situación a nivel Europeo es similar, cultivándose en la actualidad 260.000 hectáreas de judía seca, 4 millones de hectáreas menos que hace 50 años (Figura 7), y disminuyendo poco la producción hasta las 500.000 toneladas actuales (Figura 8) gracias al mejor rendimiento que en la actualidad es de $1.900 \mathrm{~kg} / \mathrm{ha}$ y al incremento anual que se viene produciendo de $36 \mathrm{~kg} / \mathrm{ha}$. A nivel mundial la situación es distinta, estando el cultivo de la judía en constante incremento en la serie estudiada, cultivándose en la actualidad 29 millones de hectáreas (Figura 10) que producen 23,7 millones de toneladas (Figura 11). En cuanto a las importaciones, en España ascienden a 47.000 toneladas, lo que supone más del $85 \%$ del consumo nacional de judía seca (Figura 6). En Europa se importan 587.000 toneladas lo que representa el $60 \%$ de la judía seca consumida (Figura 9).

La superficie cultivada de habas en España (Figura 4) ha ido disminuyendo hasta 1998 donde hubo una tendencia a la estabilización siendo en 2013 de 17.500 hectáreas. Andalucía destaca en el cultivo de habas en España, fundamentalmente Sevilla. También en Europa (Figura 7) y el mundo (Figura 10) la superficie de habas ha ido disminuyendo hasta 214.000 y 2,3 millones de hectáreas, respectivamente. Los rendimientos medios obtenidos son $1.600 \mathrm{~kg} /$ ha en España, 2.700 en Europa y 1.800 en el mundo. Los principales países productores en Europa son Francia, Reino Unido e Italia que, en conjunto, suponen más del $70 \%$ de la producción, mientras que a nivel mundial China lidera la producción de habas. La importaciones son bajas tanto en España ( 4.800 toneladas, $16 \%$ del consumo) como en Europa (85.000 toneladas, $25 \%$ del consumo) (Figuras 6 y 9 ).
La superficie cultivada de lenteja en España ha disminuido en los últimos 50 años (Figura 4) siendo en 2013 de 31.000 hectáreas. Las casi 41.000 toneladas producidas anualmente (Figura 5) no abastecen la demanda nacional por lo que importamos el $60 \%$ de la lenteja que se consume en España (Figura 6). El cultivo lenteja en España está liderado por Castilla la Mancha, y España es el principal país productor de Europa. En Europa, la superficie cultivada en la actualidad está en torno a las 80.000 hectáreas (Figura 7), la producción es superior a 91.000 toneladas (Figura 8) y las importaciones (Figura 9) son de 226.000 toneladas, lo que representa el $80 \%$ del consumo. La situación a nivel mundial es distinta, con un aumento del cultivo que llega hoy a 4,4 millones de hectáreas (Figura 10). Los mayores productores son Canadá y la India, con más del $60 \%$ del total. El cultivo de la lenteja es el único que en estos años en España no ha experimentado un incremento de rendimientos, siendo de $1.300 \mathrm{~kg} / \mathrm{ha}$, aun así, ligeramente superiores a los rendimientos medios en Europa (1.100 kg/ha) y el mundo (1.200 kg/ha).

El garbanzo también es una leguminosa muy consumida tradicionalmente en España a pesar de lo cual, como ocurría con la lenteja, su cultivo disminuye con lo que aumentan las importaciones (75\% del consumo, Figura 6). Se cultivan 27.000 hectáreas que producen 26.000 toneladas, pero importamos 75.000, (Figuras 4 y 5). La zona más productora es Andalucía, seguida de Castilla y León. En Europa el cultivo de garbanzo también es minoritario y sigue en descenso (146.000 hectáreas que producen 156.000 toneladas, Figuras 7 y 8) pero en el mundo ocurre lo contrario, siendo la tercera leguminosa grano más cultivada y producida $(13,3$ millones de toneladas en 13,7 millones de hectáreas,

Figura 7. Evolución de la superficie (hectáreas) de leguminosas grano en Europa en los últimos 50 años (FAOSTAT, 2013).

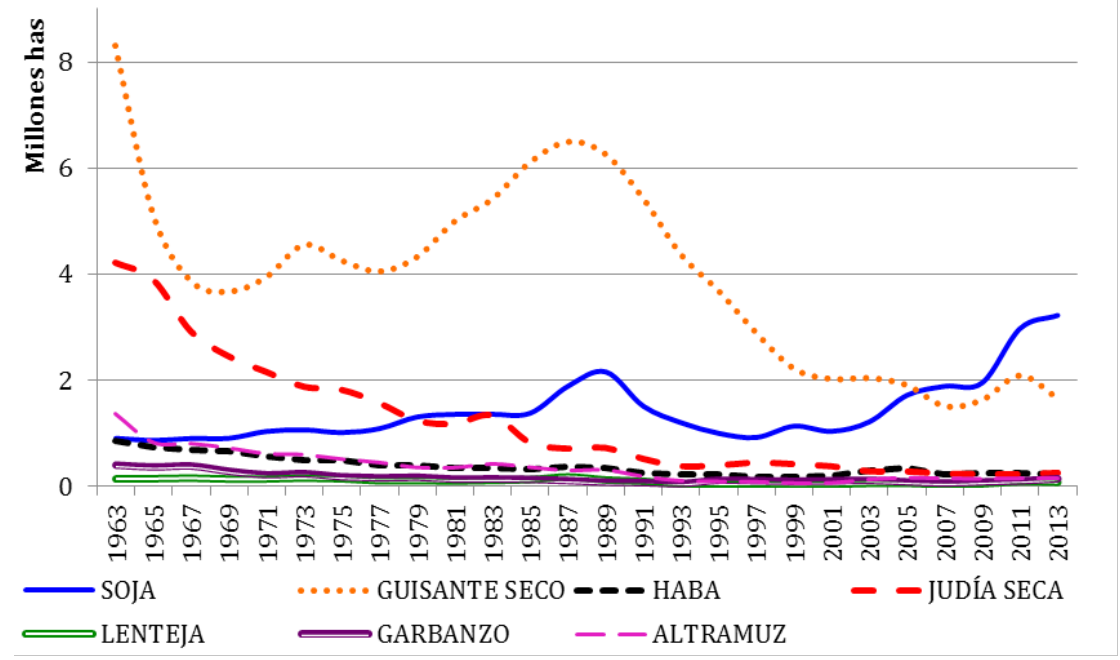


Figuras 10 y 11), situándose por encima del guisante. El $70 \%$ de la producción mundial se concentra en la India. El rendimiento del garbanzo en España es de $970 \mathrm{~kg} / \mathrm{ha}$, muy similar a la media europea (1.100 kg/ ha) y mundial ( $970 \mathrm{~kg} / \mathrm{ha}$ ), en todos los casos con una ganancia anual de entre 5 y $6 \mathrm{~kg} / \mathrm{ha} / \mathrm{año})$.

El altramuz una leguminosa grano poco cultivada en España, con 3.600 has (Figura 4) y 2.500 toneladas, representando un $1 \%$ de la superficie cultivada de leguminosas grano. En Europa se cultivan 153.000 hectáreas que producen 240.000 toneladas (Figuras 7 y 8), concentradas en Polonia ( $42 \%$ del total), Rusia (15\%) y Alemania y Bielorrusia ( $12 \%$ cada una). A nivel mundial es la leguminosa menos cultivada con 650.000 hectáreas (Figura 10) que producen en torno a 774.000 toneladas (Figura 11).
Esta dependencia de las importaciones de leguminosas, particularmente de soja, no solo supone un riesgo galopante para la balanza de pagos, sino también de seguridad alimentaria, poniendo a nuestra industria cárnica en manos de las oscilaciones del precio de la soja. Esta posición de debilidad Europea no ha hecho sino agravarse con la reciente entrada en escena de China, cuyas importaciones de soja han aumentado de forma exponencial haciendo saltar todas las alarmas sobre el riesgo de la inestabilidad de los precios. La solución no puede ser otra que el desarrollo de variedades que resulten más atractivas tanto al consumidor (calidad) como al productor (rendimiento, adaptación) a través de programas de mejora genética (Duc y col., 2015; Rubiales y col., 2015; Vaz Patto y col., 2015).

Figura 8. Evolución de la producción (toneladas) de leguminosas grano en Europa en los últimos 50 años (FAOSTAT, 2013).

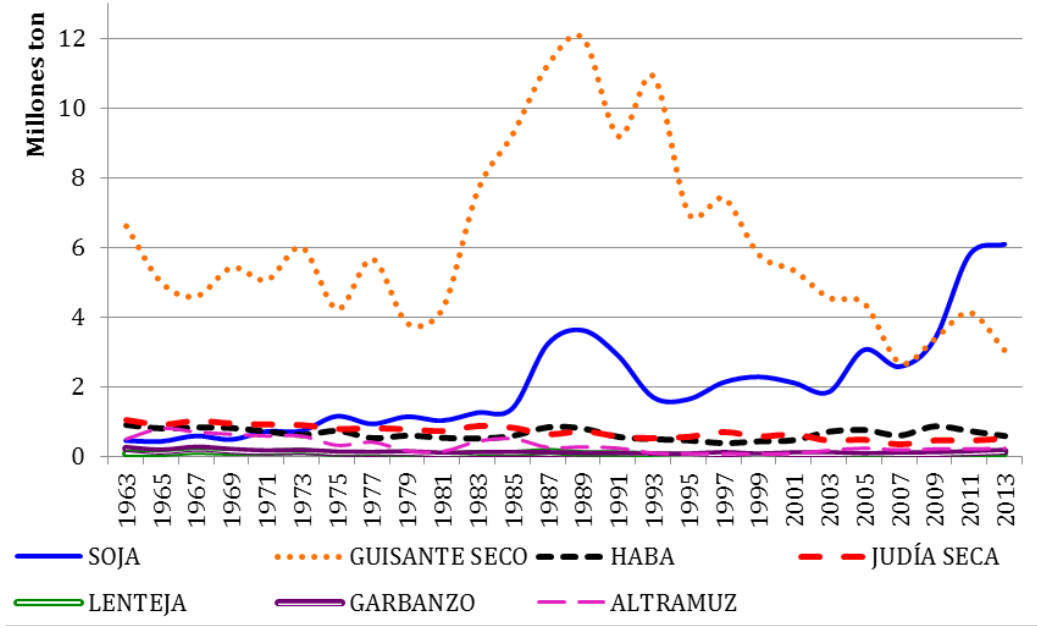

Figura 9. Evolución de las importaciones (toneladas) de leguminosas grano en Europa en los últimos 50 años (FAOSTAT, 2013). Eje Y cortado en 4 millones por cambio de escala.

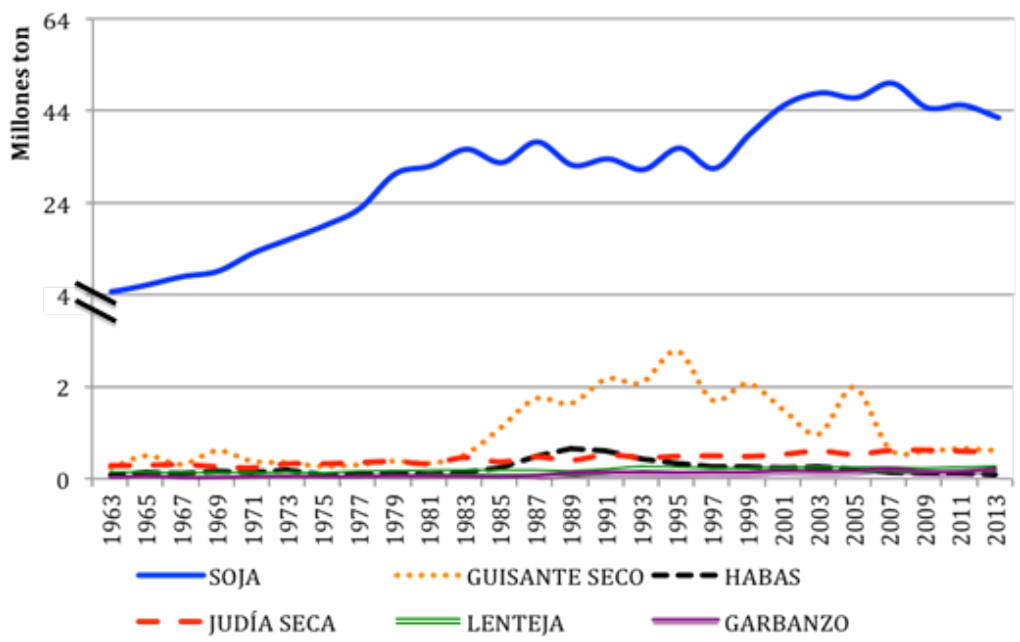


Figura 10. Evolución de la superficie (hectáreas) de leguminosas grano en el mundo en los últimos 50 años (FAOSTAT, 2013). Eje Y cortado en 20 millones por cambio de escala.

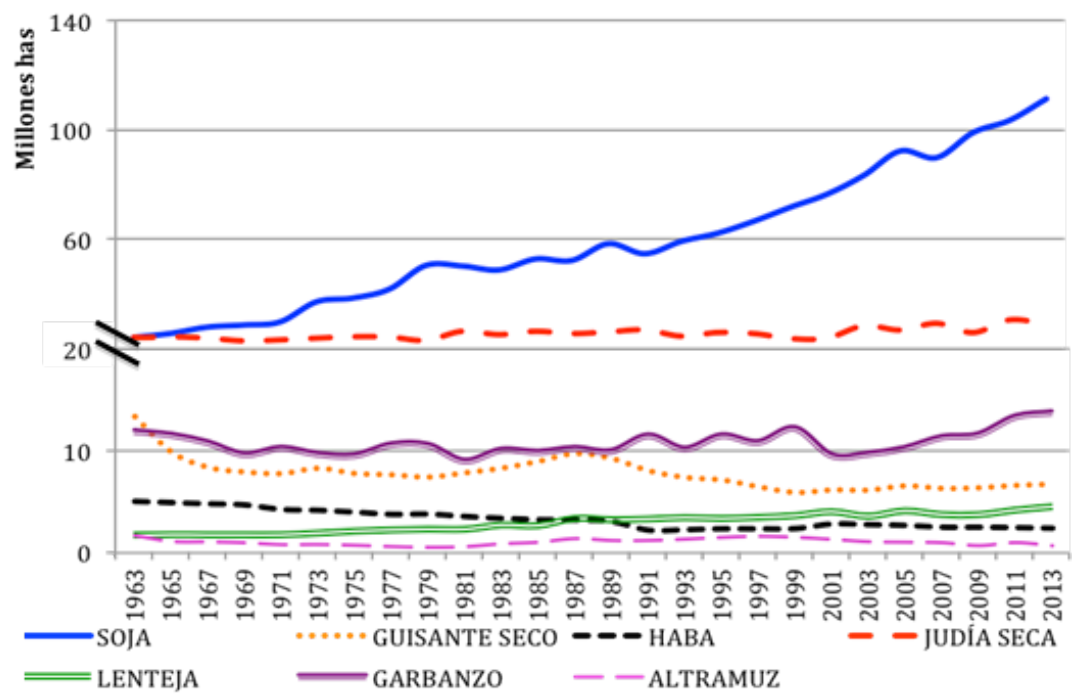

Figura 11. Evolución de la producción (toneladas) de leguminosas grano en el mundo en los últimos 50 años (FAOSTAT, 2013). Eje Y cortado en 40 millones por cambio de escala.

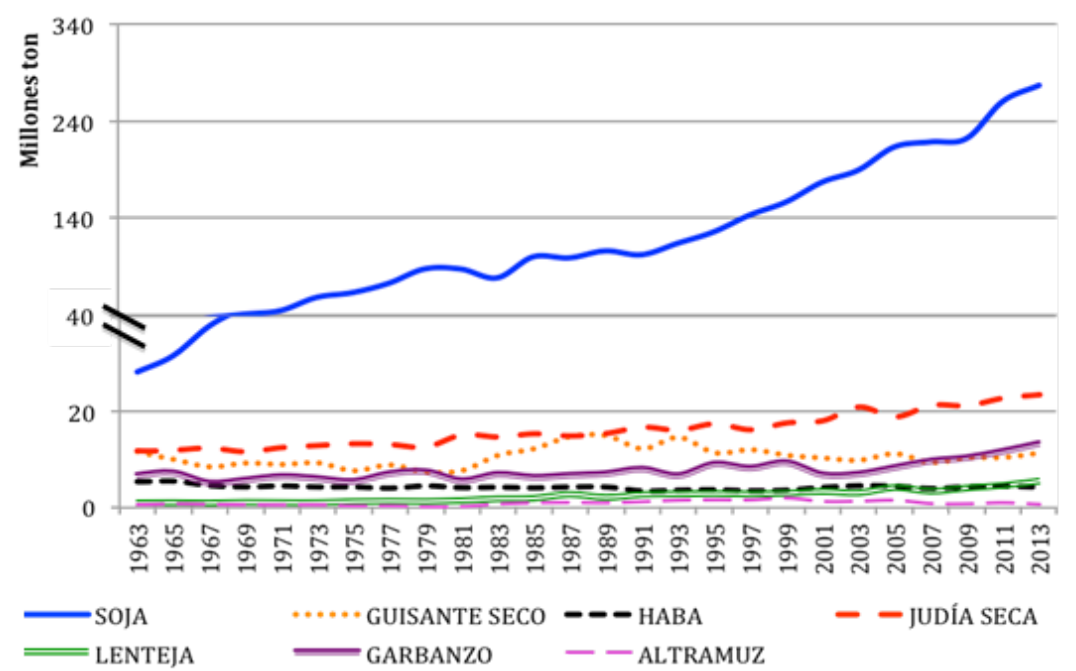

\section{BIBLIOGRAFÍA}

Arnoldi, A., Zanoni, C., Lammi, C. y Boschin, G. (2015). The role of grain legumes in the prevention of hypercholesterolemia and hypertension. Critical Reviews in Plant Sciences, 34, pp. 144168. http://dx.doi.org/10.1080/07352689.2014.897908

Delgado-Andrade, C., Olías, R., Jiménez-López, J. C. y Clemente, A. (2016). Aspectos de las legumbres nutricionales y beneficiosos para la salud humana. Arbor, 192 (779): a313. doi: http:// dx.doi.org/10.3989/arbor.2016.779n3003
Duc, G., Agrama, H., Bao, S., Berger, J., Bourion V., de Ron, A M., Gowda, C. L. L., Mikic, A., Millot, D., Singh, K., Tullu, A., Vandenberg, A., Vaz Patto, M. C., Warkentin, T. y Zong, X. (2015). Breeding annual grain legumes for sustainable agriculture: new methods to approach more complex traits and target new cultivar ideotypes. Critical Reviews in Plant Sciences, 34, pp. 381-411. http://dx.doi.org/10.1080/0735 2689.2014.898469 
Ramírez-Bahena, M. H., Peix, A., Velázques, E. y Berdmar, E. (2016). Historia de la investigación en la simbiosis leguminosa-bacteria: una perspectiva didáctica. Arbor, 192 (779): a319. doi: http:// dx.doi.org/10.3989/arbor.2016.779n3009

Rubiales, D. y Mikic, A. (2015). Introduction: legumes in sustainable agriculture. Critical Reviews in Plant Sciences, 34, pp. 2-3. http:// dx.doi.org/10.1080/07352689.2014.897896

Rubiales, D., Fondevilla, S., Chen, W., Gentzbittel, L., Higgins, T. J. V., Castillejo, M. A., Singh, K. B. y Rispail, N. (2015). Achievements and challenges in legume breeding for pest and disease resistance. Critical Reviews in Plant Sciences, 34, pp. 195-236. http:// dx.doi.org/10.1080/07352689.2014.898445
Rubio, L. A. y Molina, E. (2016). Las leguminosas en alimentación animal. Arbor, 192 (779): a315. doi: http://dx.doi. org/10.3989/arbor.2016.779n3005

Vaz Patto, M. C., Amarowicz, R., Aryee, A. N. A., Boye, J. I., Chung, H. J., Martín-Cabrejas, M. A. y Domoney, C. (2015). Achievements and challenges in improving the nutritional quality of food legumes. Critical Reviews in Plant Sciences, 34, pp. 105-143. http://dx.doi.org/10.1080/07352689.2014.897907

\section{Recursos de Internet}

FAOSTAT 2013 [en línea]. [Fecha de consulta: 15 de enero de 2016]. Disponible en: www.faostat.fao.org 